\title{
nature
}

\section{Not the last word on}

\section{the BSE crisis}

The publication of apparently conclusive evidence linking BSE in cattle to CJD in humans strengthens the case for a full review of how the BSE issue was handled. Britain would not be the only beneficiary.

f politics was an exact science, then the two papers published in this week's issue on the relationship between bovine spongiform encephalopathy (BSE) in cattle and Creutzfeldt-Jakob disease (CJD) in humans might be read as the final chapter - if not the postscript - in an unhappy saga which opened almost exactly ten years ago. Both papers, one based on work carried out by a team headed by Moira Bruce at the Institute of Animal Health in Edinburgh, the other by researchers led by John Collinge at St Mary's Hospital in London, point in the same direction, namely that the agent responsible for the two diseases is identical, and that the human disease was contracted from eating contaminated beef (see pages 498-501, 448-450 and 437-438). And both will therefore help to dispel whatever few doubts may continue to linger that alternative explanations remain possible.

But if the scientific answer to the question "can BSE cause CJD?" now appears to have been answered, many political questions are still unresolved. How did the government and its advisers react to the initial news of a possible new type of disease spreading through British herds? Was the appropriate balance struck between the need to warn consumers and a concern not to undermine a multibillion pound cattle industry? And were official actions in any way to blame for the 20 new-variant-CJD deaths that have occurred so far - an issue of critical importance to the relatives of those who have died, in their fight to recover the costs of providing medical treatment?

There are deeper issues that reach to the heart of the way in which government-funded science is organized, both in Britain and elsewhere. Is there a genuine risk that government research institutes and advisory committees may be influenced by the mission statements of the departments to which they are responsible in a way that distorts their assessment of sensitive issues? Does the BSE crisis strengthen the argument for more investment in basiclong-term research, not linked to a specific strategic objective, at such institutes? Or does it give weight to the alternative argument that such work should be done by disinterested outside groups, for example in universities?

Of course, many important lessons have already been learnt in Whitehall. There is, for example, reported to be a far greater awareness of the need to listen to external scientific experts and to make research data available to their scrutiny - even if this could have embarrassing implications. The government's long-awaited reaction to the proposals for a Food Standards Agency is likely to reflect an awareness of the need to make consumer interests more broadly represented in food policy and food research. Closer attention is being paid to public statements about what ministers consider to be 'safe' or 'dangerous'. And even the new research provides no reason for believing that health measures taken in recent years to curb the spread of BSE have been inadequate.

But it is important that the issue is not left there. There is also a question of how to build public trust in the way in which the government handles scientific issues in a modern, media-based society an issue of broad interest to any industrial democracy. There is no turning back the clock, and it is important that such a review does not turn into a witch-hunt; many of those who have found themselves in the dock in recent years undoubtedly acted in what they considered to be the best public interest while struggling with incomplete scientific information. But there are still lessons to be learnt, and further changes to be made, to reduce the chances of such a major health hazard recurring. A review that keeps this goal clearly in mind, gathers the appropriate evidence and delivers a clear and impartial judgement on why mistakes were made and what can be done to avoid them, would be a welcome and refreshing step.

\section{Time for imagination in Prague}

The Czech government should not miss an opportunity to give its scientists a needed shot in the arm.

T he Czech Republic inevitably has to pay for the acts of God that befall it, the most recent being this summer's devastating floods. But it should try to leave science untouched. As in all former communist countries facing economic difficulties, science is in danger of growing old and dying out. Young people contemplating a career in research are discouraged both by low wages and by the lack of any indication that Czech science has a robust future.

In seeking ways to pay for the flood damage, the Czech government should ensure that it does not worsen the prospects for its scientific future (see page 430). Scientists should be exempt from any wage cuts, and freed from the wage freeze recently imposed on all civil servants. The government should also do what it can to ensure that bold plans by the Academy of Sciences to develop a high-power laser donated by the Max Planck Institute for Quantum Optics in Garching, near Munich, into an inter- national research facility are not put at risk.

The laser project offers Czech scientists a unique opportunity to demonstrate to Western colleagues their ability to operate the type of large-scale facility that is common in the European Union. At the same time, it will enable young researchers to play host to European guest scientists, and thus become fully integrated into the mainstream of European research. For all Czech scientists, the project could help to restore self-esteem.

It is therefore important that there is no unnecessary delay in the installation of the laser in Prague. Concrete for the special housing unit can be laid only in the autumn months. If financial uncertainty forces a one-year delay to plans to lay the foundations next month, scientists who were using the facility at Garching until it closed last spring will look elsewhere. And if this happens, an important opportunity for Czech science will have been lost. 